\title{
Comparison of P-Wave Duration and Dispersion in Mitral Valve Replacement Surgery Via Right Atrial Transseptal or Left Atrial Approach in Rheumatic Mitral Stenosis Patients
}

\author{
Hakan Gocer, MD,${ }^{1}$ Ahmet Baris Durukan, MD, Asst. Prof., ${ }^{2}$ Ahmet Unlu, MD, ${ }^{2}$ Mustafa Unal, $M{ }^{3}$ \\ ${ }^{1}$ Department of Cardiology, Medical Park Usak Hospital, Usak, Turkey; ${ }^{2}$ Department of Cardiovascular Surgery, Medical Park Usak \\ Hospital, Usak, Turkey; ${ }^{3}$ Department of Cardiovascular Surgery, Bicard Clinic, Bishkek, Krygyzystan
}

\section{ABSTRACT}

Background: Predisposition to atrial fibrillation in mitral valve surgery has been well demonstrated. The changes in electrocardiographic parameters $\left(\mathrm{P}_{\max }, \mathrm{P}_{\min }\right.$ and $\mathrm{P}$-wave dispersion) related to AF risk are unknown. We aimed to document the relationship between electrocardiographic changes and mitral valve replacement through right or left atrial surgical approaches.

Methods: We retrospectively studied 154 patients, who underwent mitral valve replacement surgery from 2008 to 2018. Seventy-nine patients were operated with right atriotomy and transseptal approach (Group 1), and 75 patents were operated with left atriotomy (Group 2). ECGs obtained at hospital admittance and postoperatively at 24 hours were blindly analyzed.

Results: Preoperative demographic characteristics were similar. $\mathrm{P}_{\max }, \mathrm{P}_{\min }$ and $\mathrm{P}$-wave dispersion were similar preoperatively. All parameters increased in both groups compared with the preoperative values $(P<.05)$. Postoperative $\mathrm{P}_{\max }$, $\mathrm{P}_{\min }$ and $\mathrm{P}$-wave dispersion all were statistically significantly higher with the right atrial approach $(P<.05)$. Postoperative AF also was more common in Group $1(P<.05)$.

Conclusion: Right atrial approach may lead to higher $\mathrm{P}$-wave changes and atrial arrhythmias. This may be due to more extensive surgical disruption. The changes in atrial anatomic structure can increase atrial arrhythmic propensity and can cause atrial fibrillation.

\section{INTRODUCTION}

Rheumatic mitral stenosis (MS) is mostly encountered in developing countries and atrial fibrillation (AF) is the most common atrial arrhythmia in these patients. Left atrial remodeling (dilatation and fibrosis) within the wall, disorganization of the atrial muscle fibers due to mitral valve disease and atrial inflammation secondary to rheumatic carditis lead to

Received fuly 17, 2019; accepted October 1, 2019.

Correspondence: Abmet Baris Durukan, Umit Maballesi, 2463. sokak 4/18, 06520, Cankaya/Ankara, Turkey; fax: 02762272233; +905322273814 (e-mail: barisdurukan@yahoo.com). electrical chaos and conduction disturbance within the atrial wall [Nishimura 2017]. It was documented that maximum and minimum $\mathrm{P}$-wave duration $\left(\mathrm{P}_{\max }, \mathrm{P}_{\min }\right) \mathrm{P}$-wave dispersion $(\mathrm{Pd})$ significantly were correlated with mitral valve area and mean mitral gradient. Although association between $\mathrm{Pd}$ and left atrial size was not meaningful at the beginning of the disease, it became significant, following increase in left atrial dimensions. Progressive shortening of $\mathrm{Pd}$ after percutaneous mitral balloon valvuloplasty was reported. It was hypothesized that this may be due to decrease in sympathetic activity and the regression of the pathologic changes in the atrial wall, which results in more homogeneous and organized conduction of sinus impulses. A significant correlation between $\mathrm{P}_{\max }$ and $\mathrm{Pd}$ with mean diastolic gradient of the mitral valve previously was reported [Kazemi 2014]. Interatrial electromechanical delay also is longer in MS patients and is correlated with Pd [Demirkan 2013]. Inflammatory response also affects atrial structure and results in $\mathrm{P}$-wave parameter changes [Van Wagoner 2018].

Postoperative AF (POAF) still is an issue following cardiac surgery. Its incidence changes with surgical procedure and is as high as $40 \%-50 \%$ in valve surgery patients. It is associated with early and late mortality, increased risk of stroke, and increased health care costs. For prevention, antiarrhythmic or anti-inflammatory medications are prescribed [O'Brien 2019]. Despite prophylactic regimens, routine prevention protocols are not employed in most cardiac surgery units. Moreover, etiopathology of POAF is not clearly demonstrated, which may affect surgeons' preferences. In this study, we aimed to document perioperative $\mathrm{P}$-wave changes in mitral valve replacement surgery and compare right and left atrial approaches.

\section{MATERIALS AND METHODS}

This retrospective study was performed at the Bicard clinic in Bishkek, Kyrgyzstan and Private Usak Medical Hospital in Usak, Turkey. The Institutional Ethics Committees of Bicard clinic and Scientific Board of Medical Park Usak Hospital approved the study protocol, waiving informed consent based on its retrospective nature. The study was conducted, according to the latest version of Helsinki Declaration. Patients with severe rheumatic mitral stenosis who underwent mitral valve replacement surgery with mechanical prosthesis from 2008 to 
Table 1. Preoperative characteristics of patients

\begin{tabular}{|c|c|c|c|}
\hline Age & $35.25 \pm 4.99$ & $36.13 \pm 5.62$ & $.306 *$ \\
\hline Male & $36(54.4 \%)$ & $39(52.0 \%)$ & $.425 \dagger$ \\
\hline Female & $43(45.6 \%)$ & $36(48.0 \%)$ & \\
\hline LV EF (\%) & $52.37 \pm 5.77$ & $52.07 \pm 5.46$ & $.741 *$ \\
\hline PASP (mm Hg) & $39.19 \pm 7.23$ & $38.89 \pm 6.58$ & $.835 *$ \\
\hline RA diameter (mm) & $3.88 \pm 0.59$ & $3.82 \pm 0.55$ & $.524 *$ \\
\hline LA diameter $(\mathrm{mm})$ & $4.22 \pm 0.59$ & $4.21 \pm 0.62$ & $.883 *$ \\
\hline Paroxysmal AF & $22(27.8 \%)$ & $17(22.7 \%)$ & $.460 \dagger$ \\
\hline$P_{\max }(m s e c)$ & $221.97 \pm 14.96$ & $222.89 \pm 14.78$ & $.702 *$ \\
\hline P-wave dispersion (msec) & $101.25 \pm 16.70$ & $102.60 \pm 16.24$ & $.613 *$ \\
\hline
\end{tabular}

BMI: Body Mass Index, LVEF: Left ventricular ejection fraction, LA: Left atrium, PASP: Pulmonary artery systolic pressure, AF: Atrial fibrillation *Independent sapmples t-test

$\dagger$ Atrial and/or ventricular extrasystole

Table 2. Intraoperative characteristics of patients

\begin{tabular}{lccc}
\hline & Right atriotomy transseptal approach $(\mathrm{N}=79)$ & Left atriotomy approach $(\mathrm{N}=75)$ & $P$ \\
\hline Prosthetic valve size & $28.32 \pm 3.21$ & $28.68 \pm 3.30$ & $.490^{*}$ \\
Cross clamp time (min) & $54.39 \pm 5.65$ & $52.37 \pm 3.09$ & $.007^{*}$ \\
CPB time (min) & $66.16 \pm 9.93$ & $65.32 \pm 7.42$ & $.553^{*}$ \\
Revision for hemorrhage & $1(1.3 \%)$ & $.328 \dagger$ \\
\hline
\end{tabular}

\footnotetext{
CPB: Cardiopulmonary bypass

*Independent samples t-test

tchi-square
}

2018 were retrospectively analyzed. All patients were in sinus rhythm preoperatively. Exclusion criteria were concomitant coronary artery disease, additional valvular pathology rather than functional tricuspid regurgitation, dilated cardiomyopathy, coexisting bundle branch block, rhythm other than sinus rhythm, chronic obstructive pulmonary disease, renal failure, anti-arrhythmic medication use (including beta-blockers), and redo procedures. All patients were operated by the same surgeon in each clinic, with either a right transseptal or left atrial approach based on the surgeon's preference. The choice of approach mostly was transseptal in Bishkek, whereas it was left atrial in Usak.

The preoperative first admittance and postoperative 24th hour surface 12 leads ECGs were obtained and blindly analyzed by an experienced cardiologist, using magnifiers to eliminate any measurement mistake. A 12-lead ECG (AT-102, Schiller AG, and Baar, Switzerland) was recorded. Recordings were acquired at a paper speed of $50 \mathrm{~mm} / \mathrm{s}$, with $1 \mathrm{mV} /$ $\mathrm{cm}$ standardization. $\mathrm{P}_{\max }$ and $\mathrm{P}_{\min }$ were calculated from the standard ECG, during sinus rhythm. Longest and shortest $\mathrm{P}$-wave durations in 3 beats were studied for measurements. $\mathrm{Pd}$ is derived by subtracting the $\mathrm{P}_{\text {min }}$ from $\mathrm{P}_{\text {max }}$ in any of the 12 ECG leads. P-wave onset is determined as the initial deflection from the isoelectric baseline defined by the T-P segment and the $\mathrm{P}$-wave offset is defined as the junction of the end of the $\mathrm{P}$ wave and its return to baseline [Magnani 2010].

Atrial fibrillation was diagnosed based on ECG. All patients were ECG monitored in the intensive care unit and 
Table 3. Postoperative characteristics of patients

\begin{tabular}{lccc}
\hline & Right atriotomy transseptal approach $(\mathrm{N}=79)$ & Left atriotomy approach $(\mathrm{N}=75)$ \\
\hline ICU LOS (hours) & $46.92 \pm 10.69$ & $47.41 \pm 10.78$ & $.778^{*}$ \\
HLOS (days) & $6.08 \pm 1.22$ & $5.96 \pm 1.23$ & $.560^{*}$ \\
$\mathrm{AF}$ & $33(41.7 \%)$ & $18(24.0 \%)$ & $.019^{* *}$ \\
Other arrhythmiast† & $9(11.4 \%)$ & $8(10.7)$ & $.886^{* *}$ \\
$P_{\text {min }}$ (msec) & $175.89 \pm 46.95$ & $161.24 \pm 41.42$ & $.041^{*}$ \\
$P_{\text {max }}$ (msec) & $320.21 \pm 31.28$ & $287.69 \pm 32.08$ & $.000^{*}$ \\
P-wave dispersion (msec) & $144.31 \pm 42.08$ & $126.45 \pm 37.17$ & .006 \\
In-hospital mortality & 1 & $.328 \dagger$ \\
\hline
\end{tabular}

ICU: Intensive care unit length of stay, HLOS: Hospital length of stay, AF: Atrial fibrillation

*Independent samples t-test

†chi-square

$\dagger \dagger$ Atrial and/or ventricular extrasystole

Table 4. Comparison of p-wave parameters between groups

\begin{tabular}{|c|c|c|c|}
\hline \multicolumn{4}{|c|}{ Right atriotomy transseptal approach $(\mathrm{N}=79)$} \\
\hline$P_{\max }(\mathrm{msec})$ & $221.97 \pm 14.96$ & $320.21 \pm 31.28$ & .000 \\
\hline P-wave dispersion (msec) & $101.25 \pm 16.70$ & $144.31 \pm 42.08$ & .000 \\
\hline$P_{\min }(\mathrm{msec})$ & $120.29 \pm 10.79$ & $161.24 \pm 41.42$ & .000 \\
\hline$P_{\max }(m s e c)$ & $222.89 \pm 14.78$ & $287.69 \pm 32.08$ & .000 \\
\hline P-wave dispersion (msec) & $102.60 \pm 16.24$ & $126.45 \pm 37.17$ & .000 \\
\hline
\end{tabular}

*Paired samples t-test

in the ward for the first 48 hours. After 48 hours, ECG was requested if irregular pulse, palpitation or symptoms related with possible $\mathrm{AF}$ were detected.

If POAF was diagnosed, intravenous metoprolol was given for rate control. For control of rhythm, intravenous amiodarone was given $(300 \mathrm{mg}$ loading dose in 1 hour, followed by $900 \mathrm{mg}$ in 24 hours). Then for maintainance, oral amiodarone (3X200 mg) was given. In refractory cases, 450 $\mathrm{mg}$ additional infusion was administered for the next 12 hours. If sinus rhythm was not maintained in 48 hours, DC cardioversion was performed. Low molecular weight heparin was given. If sinus rhythm was not maintained after that, oral warfarin was given.

Statistical analysis: Statistical analyses were performed using SPSS software for Windows version 17.0 (Statistical Package for the Social Sciences Inc, Chicago, IL, USA). Continuous variables were expressed as 'mean values \pm standard deviation (SD).' Categorical variables were expressed as number and percentages. Characteristics were compared using "independent samples t-test" for continuous variables, and 'chi-square test' for categorical variables. Statistical significance was set as ' $P<.05$.'

\section{RESULTS}

We retrospectively studied 154 patients and divided them into 2 groups: the right atrial transseptal approach (Group $1, \mathrm{~N}=79$ ) and left atrial approach (Group 2, $\mathrm{N}=75$ ). The preoperative characteristics of the patients were similar in both groups. (Table 1) The mean age of the patients were $35.25 \pm 4.99$ and $36.13 \pm 5.62$ in Groups 1 and 2, respectively. There were $36(54.4 \%)$ male and $43(45.6 \%)$ female patients in Group 1, and $39(52.0 \%)$ male and $36(48.0 \%)$ female patients in Group 2. Body mass index, left ventricular ejection fraction, pulmonary artery systolic pressure, and left and right atrial dimensions also were studied, where similar. 
Preoperative $\mathrm{P}_{\min }$ was $120.72 \pm 11.4, \mathrm{P}_{\max } 221.97 \pm 14.96$, and $\mathrm{Pd} 101.25 \pm 16.70 \mathrm{msec}$ in Group 1, while $120.29 \pm 10.79$, $222.89 \pm 14.78$, and $102.60 \pm 16.24$ in Group 2, respectively. There was no statistically significant difference between the groups. Preoperative paroxysmal AF and other arrhythmias (atrial and ventricular extrasystole) were similar in both groups.

Perioperative characteristics are shown in Table 2. The aortic cross-clamp was higher in Group $1(P<.05)$ while cardiopulmonary bypass $(\mathrm{CPB})$ times were similar $(P>.05)$. Intensive care unit and hospital lengths of stay also were comparable between the groups.

When postoperative $\mathrm{P}$-wave changes were analyzed (Tables 3 and 4), they were statistically significantly higher in Group 1. $\mathrm{P}_{\text {min }}$ was $175.89 \pm 46.95, \mathrm{P}_{\max }$ was $320.21 \pm 31.28$, and $\mathrm{Pd}$ was $144.31 \pm 42.08 \mathrm{msec}$ in Group 1, while $161.24 \pm 41.42$, $287.69 \pm 32.08$, and $126.45 \pm 37.17$ in Group 2, respectively $(P<.05$ for each). Postoperative $\mathrm{AF}$ was more common in Group 1 (41.7\% versus $24.0 \% ; P<.05)$, while other arrhythmias were similar in both groups.

\section{DISCUSSION}

The mitral valve surgical approach is the right atrial and transseptal approach. Every surgeon mainly has a "one fits all" approach based on his/her experience, with except some exceptions. However, it's also very critical to state the advantages of the transseptal approach here. The visualization of the mitral valve is straightforward from median sternotomy compared with the right lateral exploration of the valve. It also provides concomitant tricuspid valve surgery from the same incision.

Postoperative AF following cardiac surgery is still a popular era of research since it is very common and causes deterioration in atrial and subsequently ventricular pumping which leads to an increase in perioperative morbidity and mortality [Durukan 2014; Lomivorotov 2016]. Specifically, mitral valve replacement surgery for MS is unique, since the disease process itself and surgery increases the risk [Mehta 2018; Iung 2018]. We hypothesized that a right atrial approach causes more disruption in atrial anatomy, due to transseptal nature compared with a left atrial approach, and we documented by $\mathrm{P}$-wave duration and dispersion changes that risk of $\mathrm{AF}$ is more common in a right atrial approach. However, there are conflicting results on this subject. It previously was documented that a transseptal approach increases risk of AF, where cross-clamp and $\mathrm{CPB}$ times were also longer [Rezahosseini 2015]. They have compared 163 transseptal and 652 left atrial-approached mitral valve procedures. Because incisions are longer, closing times are longer. This also may lead to more bleeding. In contrast to our study, a recent study compared 135 transseptal and 882 left atrial-approached mitral valve procedures, where incidence of $\mathrm{AF}$ was similar [Mutjaba 2018]. Guadino et al compared 146 patients undergoing mitral valve surgery with a left atrial and transseptal approach. They have documented increased cross-clamp and CPB times, but similar AF rates [Gaudino 1997]. Similarly, in a study comparing 273 left atrial and 258 transseptal approach patients, the incidence for PAF was similar [Nienaber 2006]. In our study, only cross-clamp time was longer, but $\mathrm{CPB}$ times were similar. The reoperation rate for bleeding also was similar. However, the incidence for POAF was higher in a transseptal approach.

It previously was reported that the damage caused by surgical incisions initiates an inflammatory scar process and leads to deviations in atrial wall contractions and cardiac hemodynamics structurally and $\mathrm{P}$-wave changes electrophysiologically [Wong 2004]. We believe our findings are consistent with this fact, where the right atrial approach group had higher incidence of $\mathrm{AF}$, due to more extensive cardiotomy. With surgical injury and stress, a systemic inflammatory response is activated. It previously was documented that this inflammation also is proven with increased inflammatory markers, which are proportional to intensity stress, surgical wound area, and pain [Takenaka 2006]. This local inflammatory reaction contributes to development of POAF [Toutouzas 2009].

$\mathrm{P}$-wave duration is a simple measurement that can be performed by 12 lead surface ECG. It correlates well with longest duration of right atrial ECG and deflections of right atrium. It is also a surrogate of intra and interatrial conduction time [Okutucu 2016]. Moreover, $\mathrm{Pd}$ is a recent contribution to ECG parameters and has gained popularity since it is an estimate $\mathrm{AF}$ risk in cardiac and even non-cardiac patients [Aytemir 2000]. Pd also negatively correlates with $\mathrm{P}_{\min }$ and positively with $\mathrm{P}_{\max }$. It can estimate heart damage and predisposition to arrhythmias. Simple 12 lead ECG makes these estimations possible and helps with prediction of atrial arrhythmias [Okutucu 2016]. Our study employed 12 lead surface ECG to detect and compare P-wave changes, namely $\mathrm{P}_{\max }, \mathrm{P}_{\min }$ and $\mathrm{Pd}$ and documented an increase in all parameters via right atrial approach.

In conclusion, novel $\mathrm{P}$-wave parameters namely $\mathrm{P}_{\min }, \mathrm{P}_{\max }$ and $\mathrm{Pd}$ have been shown to correlate well with postoperative $\mathrm{AF}$, and we also documented parallel findings. It may be suggested that in patients undergoing mitral valve surgery, ones with longer Pd may be directed to a left atrial approach to decrease occurrence of atrial arrhythmias since it causes less surgical damage to atrial walls.

Limitations: The study is retrospective in nature and comprises patients operated by two different surgeons and surgeon specific variability was not studied. Despite the universal techniques used, there may be personal preferences that may not be reflected. Study of more uniform patient profiles may be more conclusive in this subject.

\section{REFERENCES}

Aytemir K, Ozer N, Atalar E, Sade E, Aksöyek S et al. 2000. P wave dispersion on 12-lead electrocardiography in patients with paroxysmal atrial fibrillation. Pacing Clin Electrophysiol 23: 1109-12.

Demirkan B, Guray Y, Guray U, Ege MR, Kisacik HL et al. 2013. The acute effect of percutaneous mitral balloon valvuloplasty on atrial electromechanical delay and p-wave dispersion in patients with mitral stenosis. Herz. 38:210-5. 
Durukan AB, Gurbuz HA, Unal EU, Tavlasoglu M, Durukan E et al. 2014. Role of neutrophil/lymphocyte ratio in assessing the risk of postoperative atrial fibrillation. J Cardiovasc Surg (Torino) 55:287-93.

Gaudino M, Alessandrini F, Glieca F, Martinelli L, Santarelli P et al. 1997. Conventional left atrial versus superior septal approach for mitral valve replacement. Ann Thorac Surg 63:1123-7.

Iung B, Leenhardt A, Extramiana F. 2018. Management of atrial fibrillation in patients with rheumatic mitral stenosis. Heart 104:1062-8.

Kazemi B, Rostami A, Aslanabadi N, Ghaffari S. 2014. Electrocardiographic p-wave indices as a useful tool to predict successful percutaneous balloon mitral valvotomy in patients with mitral stenosis. J Cardiovasc Thorac Res 6:9-14.

Lomivorotov VV, Efremov SM, Pokushalov EA, Karaskov AM. 2016. New onset atrial fibrillation after cardiac surgery: pathophysiology, prophylaxis and treatment. J Cardiothorac Vasc Anesth. 30:200-16.

Magnani JW, Mazzini MJ, Sullivan LM, Williamson M, Ellinor PT et al. 2010. p-wave indices, distribution and quality control assessment (from the Framingham Heart Study). Ann Noninvasive Electrocardiol 15:77-84.

Mehta CK, McCarthy PM, Andrei AC, Kruse J, Shi H et al. 2018. De novo atrial fibrillation after mitral valve surgery. J Thorac Cardiovasc Surg 156:1515-25.

Mutjaba SS, Clark SC. 2018. Extended trans-septal versus left atrial approach in mitral valve surgery: 1017 patients' experience. Heart Asia. 10:e011008.

Nienaber JJ, Glower DD. 2006. Minitransseptal versus left atrial approach to the mitral valve: a comparison of outcomes. Ann Thorac Surg 82:834-9.
Nishimura RA, Otto CM, Bonow RO, Carabello BA, Erwin JP 3rd et al. 2017. 2017 AHA/ACC focused update of the 2014 AHA/ACC guideline for the management of patients with valvular heart disease: A report of the American College of Cardiology/American Heart Association task force on clinical practice guidelines. Circulation. 135:e1159-95.

O'Brien B, Burrage PS, Ngai JY, Prutkin JM, Huang CC et al. 2019. Society of Cardiovascular Anesthesiologists/European Association of Cardiothoracic Anaesthetists practice advisory for the management of perioperative atrial fibrillation in patients undergoing cardiac surgery. $\mathrm{J}$ Cardiothorac Vasc Anesth 33:12-26.

Okutucu S, Aytemir K, Oto A. 2016. P-wave dispersion: What we know till now? JRSM Cardiovasc Dis 5:2048004016639443.

Rezahosseini O, Rezaei M, Ahmadi Tafti SH, Jalali A, Bina P et al. 2015. Transseptal approach versus left atrial approach to mitral valve: a propensity score matching study. J Tehran Heart Cent 10:188-93.

Takenaka K, Ogawa E, Wada H, Hirata T. 2006. Systemic inflammatory response syndrome and surgical stress in thoracic surgery. J Crit Care 21:48-53.

Toutouzas K, Synetos A, Drakopoulou M, Stefanadi E, Tousoulis D et al. 2009. The role of inflammation in atrial fibrillation: a myth or a fact? Am J Med Scis 338:494-499.

Van Wagoner DR, Chung MK. 2018. Inflammation, Inflammasome activation, and atrial fibrillation. Circulation 138:2243-6.

Wong T, Davlouros PA, Li W, Millington-Sanders C et al. 2004. Mechano-electrical interaction late after fontan operation; relation between p-wave duration and dispersion, right atrial size, and atrial arrhythmias. Circulation 109:2319-25. 